\title{
Management and results of early-onset scoliosis with dual magnetically controlled growing rods: Additional preliminary results of spinal fusion surgery
}

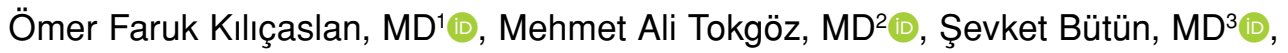 \\ Vugar Nabi, $\mathrm{MD}^{3}{ }^{(D)}$, Serdar Akalın, $\mathrm{MD}^{3}$ (D) \\ 1Department of Orthopedics and Traumatology, Antalya Training and Research Hospital, Antalya, Turkey \\ 2Department of Orthopedics and Traumatology, Ankara Keçiören Training and Research Hospital, Ankara, Turkey \\ ${ }^{3}$ Department of Orthopedics and Traumatology, Antalya Training and Research Hospital, Antalya, Turkey
}

Early-onset scoliosis (EOS) is a progressive type of spinal deformity observed before 10 years of age. It is a broad nomenclature, and various etiologies may be responsible for the occurrence of scoliosis, such as idiopathic, syndromic, congenital or neuromuscular disorders. ${ }^{[1]}$ In patients with EOS, conservative treatment methods (e.g., physical therapy, bracing, and casting) can be used to decrease the progression of the deformity in the early stages; ${ }^{[2]}$ however, if the severity of the disease increases and functional capacity is restricted, surgical treatment should be preferred to improve the quality of life of the patient. ${ }^{[3]}$

Unfortunately, spinal fusion at an early age prevents expected spinal growth and, consequently,

Received: March 08, 2021

Accepted: April 22, 2021

Published online: June 11, 2021

Correspondence: Mehmet Ali Tokgöz, MD. Antalya Eğitim ve Araştırma Hastanesi Ortopedi ve Travmatoloji Kliniği,

07100 Muratpaşa, Antalya, Türkiye.

E-mail:m.alitokgoz@gmail.com

Doi: $10.52312 /$ jdrs.2021.49

Citation: Kılıçaslan ÖF, Tokgöz MA, Bütün Ș, Nabi V, Akalın S. Management and results of early-onset scoliosis with dual magnetically controlled growing rods: Additional preliminary results of spinal fusion surgery. Jt Dis Relat Surg 2021;32(2):478-488.

(02021 All right reserved by the Turkish Joint Diseases Foundation

This is an open access article under the terms of the Creative Commons Attribution-NonCommercial License, which permits use, distribution and reproduction in any medium, provided the original work is properly cited and is not used for commercial purposes (http://creativecommons.org/licenses/by-nc/4.0/).

\section{ABSTRACT}

Objectives: The aim of this study was to evaluate the clinical and radiographic outcomes and complications of dual magnetically controlled growing rods (MCGRs) in the treatment of early-onset scoliosis (EOS) and to investigate the results of patients with definitive spinal fusion following MCGR.

Patients and methods: A total of 15 patients ( 7 males, 8 females; mean age: $8.7 \pm 1.7$ years; range, 6 to 10 years) with EOS who underwent dual MCGR and were prospectively followed between February 2013 and March 2019 were included in this retrospective study. The Cobb angle, thoracic kyphosis, and the length of the spine between T1-T12 and T1-S1 were measured on preoperative, postoperative, and follow-up radiographs. The 24-Item Early-Onset Scoliosis Questionnaire (EOSQ-24) was used to assess the functional outcomes before and after the operation. All complications during the treatment were recorded.

Results: The mean follow-up was $27.8 \pm 10.4$ (range, 12 to 60 ) months. The mean curve correction immediately after the index surgery and latest follow-up was $47.6 \%$ and $42.4 \%$, respectively $(\mathrm{p}>0.05)$. At the last follow-up, there were no significant changes in mean Cobb and kyphosis angles. The mean T1-T12 length increase was $26.2 \pm 7.1$ (range, 16 to 40 ) $\mathrm{mm}$, while the mean T1-S1 length increase was $43.3 \pm 15.0$ (range, 24 to 70 ) $\mathrm{mm}$. Complications developed in four (26.6\%) of 15 patients. Definitive spinal fusion surgery was performed in seven patients. Total mean Cobb angle difference between the final follow-up and fusion surgery was $9.3^{\circ}(\mathrm{p}=0.016)$ and kyphosis angle difference was $-2.1^{\circ}(p=0.349)$. After fusion surgery, total lengthening in $\mathrm{T} 1-\mathrm{T} 12$ and T1-S1 distance was $10.5 \mathrm{~mm}(\mathrm{p}=0.036)$ and $15.0 \mathrm{~mm}$ $(\mathrm{p}=0.022)$, respectively. A significant increase in all subdomain scores of the EOSQ-24 ( $<<0.05)$, except for financial impact, was recorded in all patients.

Conclusion: Dual MCGR technique is an effective, reliable, and robust treatment alternative for primary EOS. However, surgeons should be aware of the relatively high rate of complications. In addition, residual deformity can be corrected successfully with definitive surgery.

Keywords: Early-onset scoliosis, magnetically controlled growing rod, spinal fusion, spinal growth 
pulmonary development. As a result of the prevention of pulmonary development, thoracic insufficiency syndrome, which is defined as "the inability of the thorax to support normal respiration or lung growth", may develop in the growing child. Early spinal fusion causes a more than two-fold increase in mortality by age 40 years, compared to the general population. ${ }^{[4]}$ Also, it may lead to poor cosmetic appearance. To avoid the complications of spinal fusion in young children, growth-friendly surgical treatment strategies and techniques, such as using growing rods, have been developed. ${ }^{[5,6]}$

Currently, traditional growing rods (TGRs) are the most commonly used surgical strategies in treating advanced EOS. However, multiple anesthesia and repetitive surgeries increase the risk of complications for each additional surgical procedure by nearly $24 \% .{ }^{[7]}$ Besides, it produces a significant physiological and psychological burden for the patients and their parents. ${ }^{[7,8]}$ Magnetically controlled growing $\operatorname{rod}(\mathrm{MCGR})$ is a relatively new technique that was introduced to meet the above-mentioned needs, while reducing the number of operations and morbidity. ${ }^{[9,10]}$ Although initial reports on early outcomes of MCGR are promising, there is still a need for supportive information about the efficiency of MCGR and its complications. ${ }^{[8,10,11]}$

In the present study, we aimed to assess early radiological results of the MCGR technique and 24-Item Early-Onset Scoliosis Questionnaire (EOSQ-24) in children with EOS and to investigate the results of patients with definitive spinal fusion following MCGR, which is rarely described in the current literature.

\section{PATIENTS AND METHODS}

This single-center, retrospective study was conducted at Antalya Training and Research Hospital, Department of Orthopedics and Traumatology between February 2013 and March 2019. A total of 15 patients ( 7 males, 8 females; mean age: $8.7 \pm 1.7$ years; range 6 to 10 years) with EOS who underwent dual MCGR and were prospectively followed were retrospectively analyzed. Inclusion criteria were as follows: a diagnosis of EOS, having a thoracic height less than $22 \mathrm{~cm}$, failed non-operative treatment with any method, and progression of the curvature of more than $10^{\circ}$ over six months with a Cobb angle over $40^{\circ}$. According to our clinic consensus, in all EOS patients, bracing is initiated, until the scoliotic curve reaches the threshold for surgery of $>40^{\circ}$ to reduce the rate of progression of the deformity and to avoid the implementation of growing rods. In this study, patients who had a previous surgical intervention for spinal deformity and patient who were followed less than two years and less than three outpatient lengthening procedures were excluded from the study. A written informed consent was obtained from the parents and/or legal guardians of the patient. The study protocol was approved by the Antalya Training and Research Hospital, Ethics Committee (Date: 07.05.2020, No: 6/21). The study was conducted in accordance with the principles of the Declaration of Helsinki.

\section{Surgical technique and postoperative follow-up}

All patients were operated on prone position on a radiolucent table with neuromonitoring. The status and flexibility of the deformity was evaluated with standard, traction, and bending radiographs. The segment planned to be fused after the end of the growth was determined, and two mid-axial incisions were made on the first and end two vertebral levels of the relevant region under fluoroscopic control. Pedicle screws were inserted bilaterally on two vertebrae, both at the proximal and distal locations. Rod lengths were calculated separately for concave and convex sides by measuring the distance between proximal and distal segments. Subperiosteal dissection was performed, and magnetic rods (MAGEC Ellipse technology, Irvine, CA, USA) that bends only to a limited degree from the distal and proximal parts due to the impossibility of bending the rod in the actuator area were inserted in the submuscular layer and were connected to pedicle screws. Magnetic rods $(5.5 \mathrm{~mm}$ ) were fixed by performing distraction, compression, and derotation to the screws. Decortication was performed to provide fusion at the instrumented segments.

The patients were instructed to wear custom-made thoracolumbosacral orthosis for six months after index surgery. The lengthening was performed at an average of three-month intervals at the outpatient clinic without anesthesia or sedation. The patient was positioned in the prone position, the actuator parts of the rods were found with the aid of a magnet, and the skin levels were marked. Using a non-invasive magnetic remote control, each rod was, then, lengthened at a range of 2 to $6 \mathrm{~mm}$ by calculating the estimated length according to the DiMeglio growth velocity chart for each patient which shows annual growth velocity from T1 to L5, depending on the child's age and weight. ${ }^{[12,13]}$ The lengthening of the rods was checked and confirmed through radiographs taken before and after the procedure.

\section{Radiographic evaluations}

All measurements were performed on digital radiographs stored in the Picture Archiving and 
Communication System (PACS) of the institution using a dedicated software (Sectra IDS7, version 18.2., Sectra $\mathrm{AB}$, Linköping, Sweden) on the workstation. The coronal Cobb angle ${ }^{[14]}$ and thoracic kyphosis were measured on the preoperative posteroanterior and lateral whole-spine radiographs, and the distance between T1-T12 and T1-S1 was measured for the assessment of the length of the spine. The heights were evaluated as the perpendicular between two parallel lines passing through the centers of the upper endplate of the initial vertebrae and the lower endplate of the last vertebrae. ${ }^{[15]}$

Cobb angle, kyphosis angle, T1-T12, and T1-S1 distances were measured in the early postoperative period, as well as the final follow-up to evaluate deformity correction and maintenance of spinal growth. To provide the reliability of the measurements and minimize possible measurement errors, two independent spinal surgeons performed all measurements twice, and the average of the measurements was used for the analysis.

\section{Clinical evaluations}

Clinical outcome assessments were completed using the 24-Item Early-Onset Scoliosis Questionnaire (EOSQ-24) at baseline and the final follow-up. ${ }^{[16,17]}$ All complications during follow-up were recorded.

\section{Statistical analysis}

Statistical analysis was performed using the IBM SPSS Statistics for Windows version 23.0 software (IBM Corp., Armonk, NY, USA). Continuous variables were expressed in mean \pm standard deviation (SD) or median (min-max), while categorical variables were expressed in number and frequency. As the data did not conform to the normal distribution, the non-parametric analysis was performed. The Wilcoxon signed-rank test was used to compare preoperative, postoperative, and final follow-up data sets. A $p$ value of $<0.05$ was considered statistically significant.

\section{RESULTS}

There were 15 patients ( 8 girls, 7 boys) with a mean age of $8.7 \pm 1.7$ years (range $6-10$ years) at the time of index surgery. The mean follow-up period of the patient was 27.8 \pm 10.4 months (range: 12-60 months). The reason for the minimum followup period of 12 months was MAGEC rods were removed unexpectedly early in two patients due to complications. The etiology was idiopathic in four patients, neuromuscular in four (three cerebral palsies, one Charcot Marie Tooth disease), and congenital seven. The average surgical time was 145.3 minutes (range: 100-180).
The mean hospital stay was 5.9 days (range: 4-12 days). The mean duration between index surgery and the first distraction was 82.8 days (range: 60-98 days). The mean proximal level of instrumentation was T2-T3 (T1-T5), and the mean distal level was L3-L4 (L2-S1). Double rods (titanium $5.5 \mathrm{~mm}$ ) were used in all patients. Anchors were provided with pedicle screws, both proximally and distally. The patients underwent a total of 105 distractions and a mean of 7 distraction sessions per patient. The mean distraction interval was 86.8 days (60-117 days). Detailed data and radiological measurements of the patients were presented in Table I (Figure 1).

Mean preoperative Cobb angle was $57.9 \pm 16.7^{\circ}$ and reduced to $30.1 \pm 11.5^{\circ} \quad(\mathrm{p}<0.001)$ immediately after the index surgery and increased to $33.3 \pm 13.8^{\circ}$ at the final follow-up $(\mathrm{p}=0.334)$. The mean curve correction was $27.6^{\circ}$ between preoperative and early postoperative radiographs $(\mathrm{p}=0.001)$ and $24.6^{\circ}$ between preoperative and final follow-up $(\mathrm{p}=0.001)$ (Table II). The mean curve correction immediately after the index surgery and latest follow-up was $47.6 \%$ and $42.4 \%$, respectively.

Mean preoperative thoracic kyphosis was $29.5 \pm 14.2^{\circ}$, and reduced to $23,5 \pm 9.8^{\circ}$ immediately after the index surgery and increased to $24.9 \pm 9.5^{\circ}$ at last follow-up ( $\mathrm{p}=0.08)$. The change in thoracic kyphosis was $6^{\circ}$ between preoperative and early postoperative radiographs and $4.6^{\circ}$ between preoperative and the final follow-up. There was no statistically significant difference of thoracic kyphosis angle between any of the measurements (Table II).

The mean T1-T12 length was $189.5 \pm 20.9 \mathrm{~mm}$ preoperatively and increased to $205.2 \pm 21.1$ and $215.7 \pm 18.6$ at the early postoperative and last follow-up, respectively. While the mean T1-S1 length was $310.3 \pm 39.9 \mathrm{~mm}$ preoperatively, it was $335.7 \pm 39.1$ and $353.5 \pm 35.2 \mathrm{~mm}$ in the early postoperative and last follow-up, respectively. When corrections and extensions are included, the mean T1-T12 length increase was $26.2 \pm 7.1 \mathrm{~mm}(16-40 \mathrm{~mm})$, while the T1-S1 length increase was $43.3 \pm 15.0 \mathrm{~mm}(24-70 \mathrm{~mm})$. The average monthly T1-T12 and T1-S1 length increase were $0.95 \mathrm{~mm}$ and $1.52 \mathrm{~mm}$, respectively. Mean T1-T12 and T1-S1 lengthening after index procedure and last follow-up was $4.2 \pm 2 \mathrm{~mm} /$ year (range: 1.4 to $7.8 \mathrm{~mm} /$ year) and $6 \pm 2.7 \mathrm{~mm} /$ year (range: 1.8 to $10.8 \mathrm{~mm} /$ year), respectively. When the mean spinal lengths were compared between preoperative and postoperative radiographs, a statistically significant increase was detected between T1-T12 and T1-S1 lengths (for both; $(\mathrm{p}<0.001)$ (Table II). 


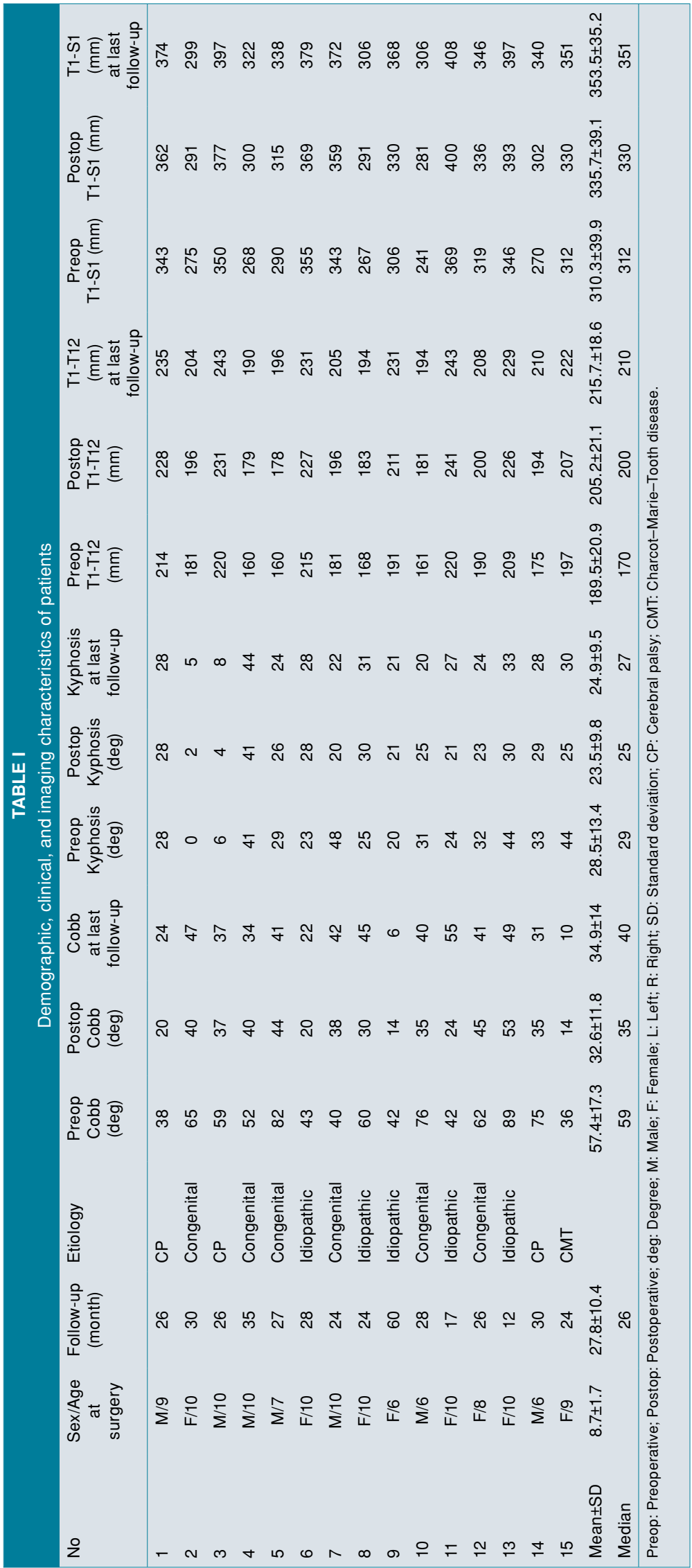



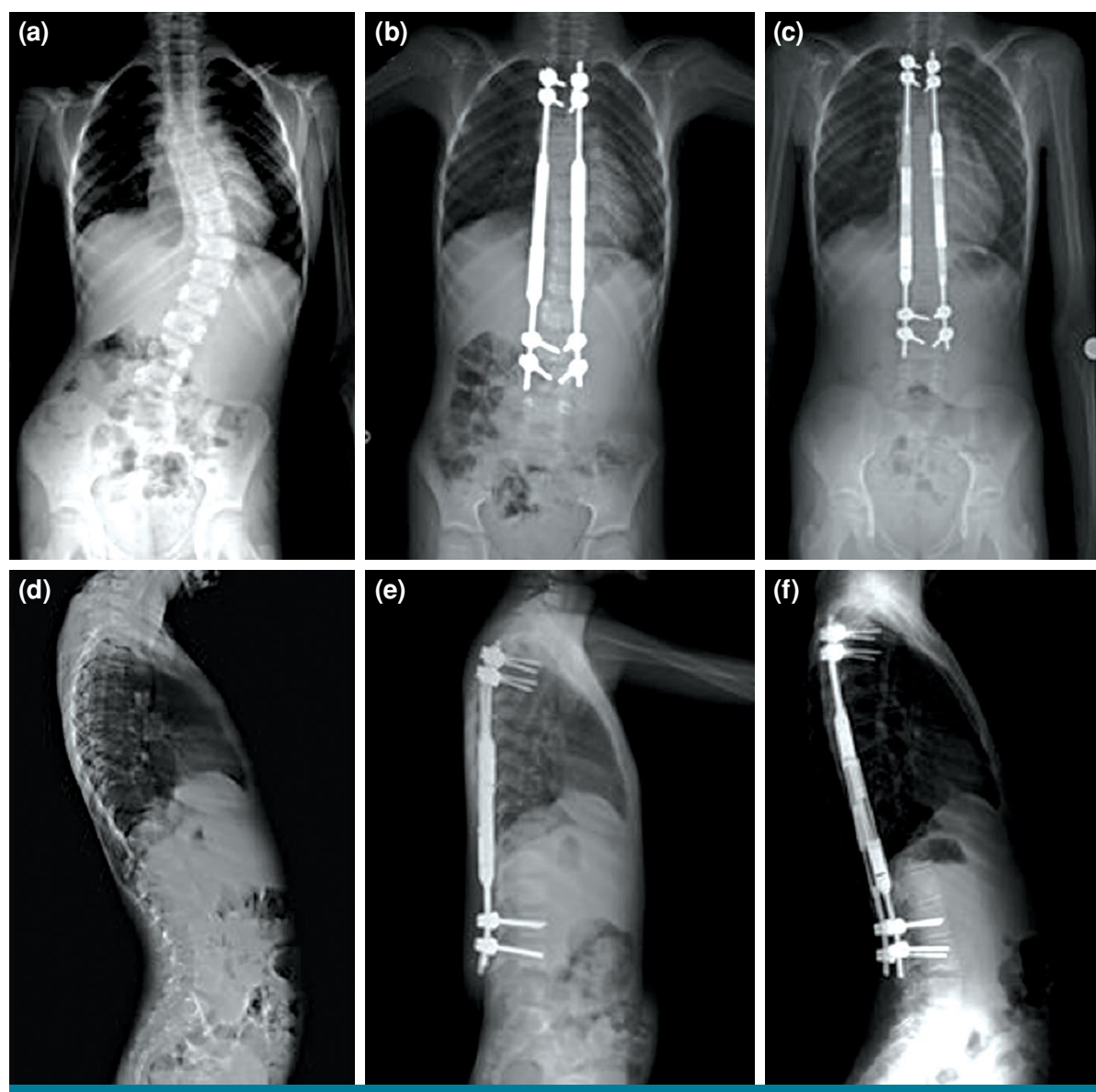

FIGURE 1. (Case 9) A six-year-old girl was admitted with early-onset scoliosis (idiopathic). A magnetically controlled growing rod was implanted between T3 and L3 spinal levels. $(\mathbf{a}, \mathbf{b}, \mathbf{c})$ Anteroposterior and (d, e, f) lateral whole-spine radiographs depicting significant correction of the coronal plane Cobb angles. Preoperative radiographs (a- Cobb angle: 42); early postoperative radiograph after index surgery (b-Cobb angle: 14 ), and final follow-up radiograph at 52 months (c- Cobb angle: 6); (d) lateral preoperative, (e) early postoperative, and (f) final follow-up at 52 months radiographs were shown. There was no significant difference about the angle of kyphosis between the preoperative and final follow-up radiographs.

The outpatient distractions were well tolerated, and no neurological complications occurred at index surgery and during the lengthening sessions. Smith complication grade 1 and 2 was developed in four
$(26.6 \%)$ of 15 patients. ${ }^{[18]}$ One patient experienced pedicle screw pull-out at the ninth postoperative month, and one patient developed backtracking of the rod at the $12^{\text {th }}$ postoperative month. One patient had

TABLE II

Comparison of functional outcomes before and after surgery

\begin{tabular}{|c|c|c|c|c|c|c|}
\hline & $\begin{array}{l}\text { Preoperative- } \\
\text { postoperative }\end{array}$ & & $\begin{array}{l}\text { Preoperative } \\
\text { last follow-up }\end{array}$ & & $\begin{array}{l}\text { Postoperative } \\
\text { last follow-up }\end{array}$ & \\
\hline & Mean difference & $p^{*}$ & Mean difference & $p^{*}$ & Mean difference & $p^{*}$ \\
\hline Cobb angle (deg.) & 24.8 & 0.001 & 22.5 & 0.001 & -2.4 & 0.681 \\
\hline Thoracic kyphosis (deg.) & 5 & 0.059 & 3.7 & 0.197 & -1.3 & 0.083 \\
\hline T1-T12 distance (mm) & -15.7 & $<0.001$ & -26.2 & $<0.001$ & -10.5 & $<0.001$ \\
\hline T1-S1 distance (mm) & -25.5 & $<0.001$ & -43.3 & $<0.001$ & -17.8 & $<0.001$ \\
\hline
\end{tabular}


a surgical wound infection, which was successfully treated with oral antibiotics and wound care. Also, one patient developed late-onset proximal junctional kyphosis. No patient encountered more than one complication, and no intraoperative complications occurred (Figure 2).

During the follow-up period, definitive spinal fusion surgery was performed in seven patients, and the date of the surgery was accepted as the last follow-up. The definitive spinal fusion was performed earlier than the scheduled time due to rod backtracking in one patient at the first postoperative year. But, the patient has almost reached her final spinal height. In patients with proximal junctional kyphosis and screw pull-out, the timing of the spinal fusion was postponed until the growth stage increased to Risser 3. The condition of the spine and implants were checked with consecutive follow-up until growth was completed. Other patient's spinal fusion surgery was performed after skeletal maturity was achieved, and spinal growth was minimal between the follow-ups. After a mean follow-up period of $21.3 \pm 5.5$ months, we achieved a distraction of $225.7 \pm 18.9 \mathrm{~mm}$ in the thoracic height at the last follow-up, and it increased to a mean of $238.4 \pm 23.4 \mathrm{~mm}$ in the post-fusion period $(p=0.047)$. Total mean coronal Cobb angle changes between final lengthening and fusion surgery were $13.8^{\circ}(p=0.022)$, changes in kyphosis angle were $3.1^{\circ}(p=0.349)$. A total lengthening in T1-T12 and T1-S1 distance was $10.5 \mathrm{~mm}(\mathrm{p}=0.036)$ and $15.0 \mathrm{~mm}$ $(\mathrm{p}=0.022)$, respectively (Table III).

Statistically, significant improvements were recorded in EOSQ-24 scores in almost all domains. When evaluating the total score of all areas, it was
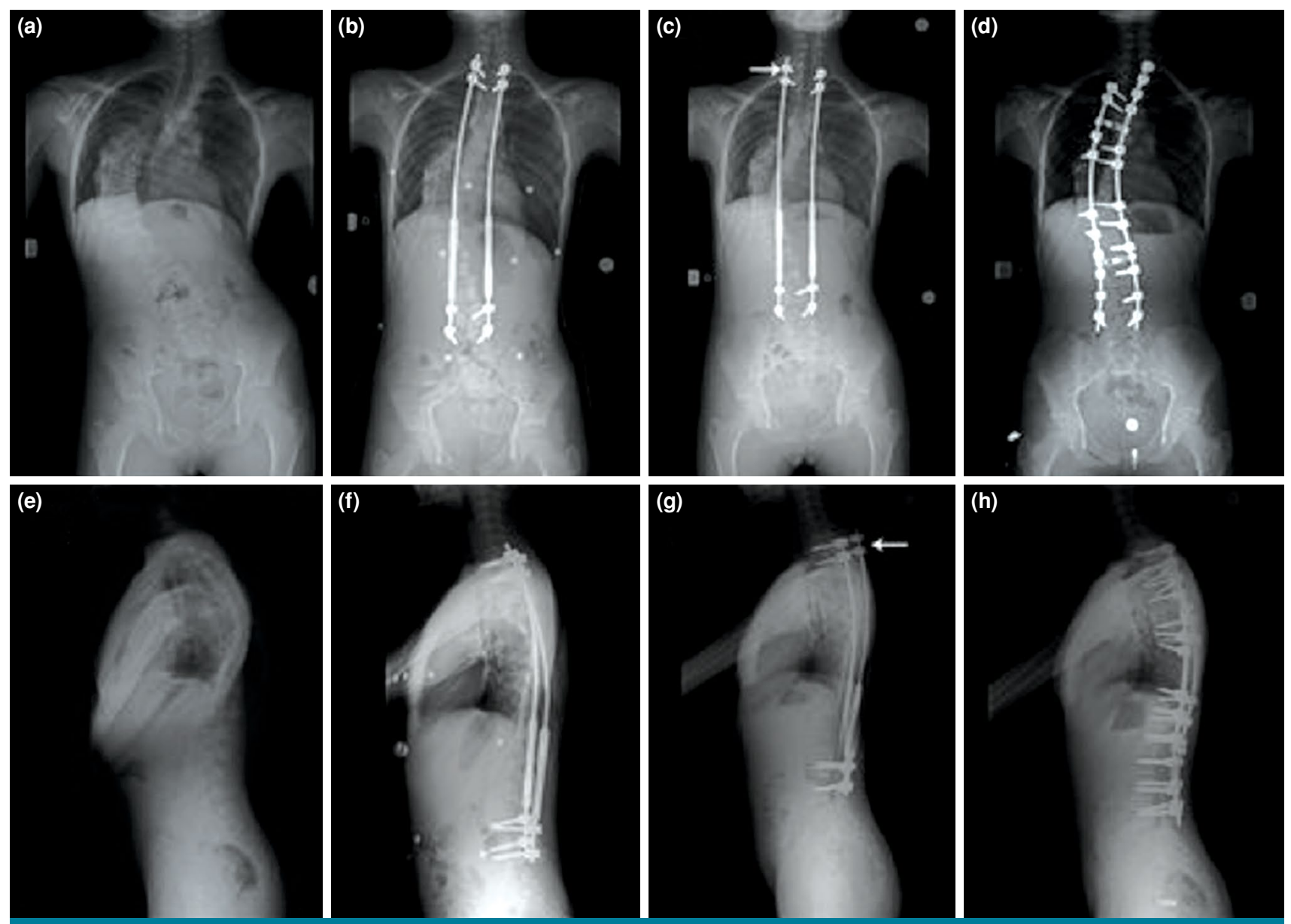

FIGURE 2. (Case 13) A 10-year-old girl was admitted with early-onset scoliosis (congenital). A magnetically controlled growing rod was implanted between T1 and L4 spinal levels. (a, b, c, d) Anteroposterior and (d, e, f, g) lateral whole-spine radiographs depicting. At postoperative ninth month, screw pull-out developed (c - Cobb angle: 45 ), at $15^{\text {th }}$ months, definitive spinal fusion was performed ( $d$ - Cobb angle: 34 ). (e) Lateral views of preoperative, (f) early postoperative, $(g)$ ninth-month radiographs with the demonstration of failed (pulled-out) screw, (h) spinal fusion surgery at $15^{\text {th }}$ month. The preoperative kyphosis angle was $44^{\circ}$, while it was $31^{\circ}$ after spinal fusion surgery. White arrows indicate the failed (pull-out) screw. 


\begin{tabular}{|c|c|c|c|c|c|c|c|c|c|}
\hline & & & ssurement v & $\begin{array}{r}\text { TAE } \\
\text { ues of patie }\end{array}$ & $\begin{array}{l}\text { E III } \\
\text { s after sp }\end{array}$ & al fusion sur & & & \\
\hline & & Cob & (deg) & Kypho & (deg) & $\mathrm{T} 1-\mathrm{T} 1$ & $(\mathrm{~mm})$ & T1-S & $(\mathrm{mm})$ \\
\hline & Duration & Last F-up & After SF & Last F-up & After SF & Last F-up & After SF & Last F-up & After SF \\
\hline 1 & 26 & 24 & 14 & 28 & 30 & 235 & 252 & 374 & 405 \\
\hline 3 & 26 & 37 & 25 & 8 & 13 & 243 & 238 & 397 & 389 \\
\hline 6 & 28 & 22 & 10 & 28 & 30 & 231 & 256 & 379 & 426 \\
\hline 7 & 24 & 42 & 39 & 22 & 45 & 205 & 227 & 372 & 400 \\
\hline 8 & 24 & 45 & 38 & 31 & 20 & 194 & 195 & 306 & 316 \\
\hline 11 & 17 & 55 & 17 & 27 & 30 & 243 & 266 & 408 & 438 \\
\hline 13 & 12 & 49 & 34 & 33 & 31 & 229 & 235 & 397 & 409 \\
\hline Mean $\pm S D$ & $21.3 \pm 5.5$ & $39.1 \pm 12.4$ & $25.3 \pm 11.9$ & $25.3 \pm 8.4$ & $28.4 \pm 10$ & $225.7 \pm 18.9$ & $238.4 \pm 23.4$ & $376.1 \pm 33.8$ & $397.6 \pm 39.5$ \\
\hline Median & - & 42 & 25 & 28 & 30 & 231 & 238 & 379 & 405 \\
\hline$p$ value & - & & & & & 0.0 & 3 * & & $28^{*}$ \\
\hline
\end{tabular}

\begin{tabular}{|c|c|c|c|c|c|c|}
\hline \multicolumn{7}{|c|}{ TABLE IV } \\
\hline & \multicolumn{2}{|c|}{ Preoperative } & \multicolumn{2}{|c|}{ Last follow-up } & \multirow[b]{2}{*}{ Mean difference } & \multirow[b]{2}{*}{$p^{*}$} \\
\hline & Mean $\pm S D$ & Median & Mean $\pm S D$ & Median & & \\
\hline General health & $62.5 \pm 23.6$ & 62.5 & $80.8 \pm 18.2$ & 87.5 & -18.8 & $<0.001$ \\
\hline Pain/discomfort & $72.5 \pm 17.2$ & 75 & $90.0 \pm 15.8$ & 100 & -25.0 & 0.005 \\
\hline Physical function & $70.0 \pm 38.6$ & 91.7 & $77.8 \pm 41.15$ & 100 & -15.8 & 0.013 \\
\hline Pulmonary function & $75.0 \pm 26.7$ & 75 & $91.7 \pm 15.4$ & 100 & -25.0 & 0.010 \\
\hline Transfer & $78.3 \pm 29.7$ & 100 & $88.3 \pm 18.6$ & 100 & -15.8 & 0.020 \\
\hline Daily living & $70.0 \pm 34.0$ & 87.5 & $82.5 \pm 26.2$ & 100 & -23.0 & 0.013 \\
\hline Fatigue/energy level & $65.0 \pm 24.2$ & 62.5 & $84.5 \pm 18.2$ & 87.5 & -25.0 & 0.004 \\
\hline Emotion & $63.3 \pm 31.9$ & 50 & $77.8 \pm 28.8$ & 87.5 & -25.0 & 0.015 \\
\hline Parental impact & $58.6 \pm 17.2$ & 65 & $67.7 \pm 12.3$ & 70 & -14.5 & 0.037 \\
\hline Financial impact & $53.3 \pm 8.8$ & 50 & $55.0 \pm 10.4$ & 50 & -25.0 & 1.000 \\
\hline Satisfaction & $57.5 \pm 28.3$ & 50 & $83.7 \pm 18.3$ & 87.5 & -37.5 & 0.003 \\
\hline Mean domain score & $66.2 \pm 20.1$ & 71.1 & $82.5 \pm 14.4$ & 86.8 & -13.8 & $<0.001$ \\
\hline
\end{tabular}

found that the initial value was $66.2 \pm 20.1$, while it increased to $82.5 \pm 14.4$ at the last control $(\mathrm{p}<0.001)$. No statistically significant improvement was observed after surgery only in the "Financial Impact" subdomain $(p>0.05)$ (Table IV).

\section{DISCUSSION}

This preliminary study investigated the radiological and functional results of MCGR in patients with EOS who underwent dual-rod distraction. The findings in this study support that MCGR allows spinal growth significantly without the need for additional surgeries. Furthermore, definitive spinal fusion surgery results following MCGR are effective in both residual deformity correction and spinal lengthening.

In the relevant literature, the correction of the Cobb angle in the MCGR technique has been reported between 27.3 and 56.7\%. . $81,10,19-21]$ Compared to the previous studies, a similar coronal plane correction (47.6\%) was achieved in the current study. The deformity stayed stable, and only $3 \%$ correction loss occurred during the treatment period, except for a patient who developed backtracking of the rod. There may be several reasons for achieving these 
almost twice different rates in different studies, such as the flexibility of the curves and single versus double rod use. Ridderbusch et al. ${ }^{[2]}$ performed MCGR in 24 children with EOS and reported a high coronal correction rate of $54 \%$. The authors attributed this high rate of correction to the patients' relatively flexible curves in their series and using the dual-rod technique. It is well-known that significant differences are seen between scoliosis types such as a patient with idiopathic scoliosis and a patient with congenital scoliosis, which have a different natural course of the disease and flexibility of the curves. Keskinen et al. ${ }^{[23]}$ compared the primary cases with conversion cases and found that they had a greater correction rate in the primary group with $24.8 \%$ versus $45.7 \%$ correction rates, respectively. Stiffness due to secondary surgeries may explain the low correction rates in conversion cases. Although a considerable coronal plane correction rate was achieved, a similar amount of correction could not be achieved on the sagittal plane in our study. The reason behind this undesirable consequence may be that it is difficult to control the sagittal profile due to the impossibility of bending the rod in the actuator area, which is an important limitation of MCGR.

Besides the correction of deformity, sufficient growth of the spine should be also obtained in EOS. In previous studies, MCGR has been shown to be an effective and successful method for increasing length, thereby, allowing reasonable spinal growth in EOS. ${ }^{[10,11,19,24]}$ Studies have demonstrated a length gain of 4 to $19 \mathrm{~mm}$ per year for length T1 -S1 and 1-14 mm per year for T1-T12. ${ }^{[8,21-23]}$ However, per the extension protocol, the optimum protocol for rod extension frequency, amount of extension, and the role of the lengthening radiographs still remain to be elucidated. ${ }^{[20,25]}$ In addition, the rule of "law of diminishing returns" with MCGR is unclear. Ahmad et al. ${ }^{[26]}$ reported that the extension rates of the MCGRs were the highest in the first year, dropped below $50 \%$ after two years, and continued to reach only $25 \%$ of the intended extension at 2.5 years. In the study conducted by Dimeglio and Canavese, ${ }^{[12]}$ the mean monthly elongation in T1-12 between the ages of five and 10 years was $1.16 \mathrm{~mm}$ and $1.2 \mathrm{~mm}$ in T1-S1. In the current study, monthly lengthening means were calculated as $0.95 \mathrm{~mm}$ for T1-12 and $1.52 \mathrm{~mm}$ for T1-S1. However, it is frequently reported that there may be a discrepancy between the planned and the actual lengthening, as the time after surgery increases. ${ }^{[8,19]}$ In our study, we observed that T1-12 increased by a mean of $23.5 \mathrm{~mm}$ and T1-S1 increased by $37.7 \mathrm{~mm}$ until the final follow-up. However, the mean T1-T12 and T1-S1 lengthening after index procedure and final follow-up was $3.96 \mathrm{~mm} /$ year and $6.24 \mathrm{~mm} /$ year, respectively. Therefore, it may be beneficial to keep the planned extension length above the expectation of physiological lengthening at the initial operation. Although there was a difference between the planned and acquired lengthening, sufficient spinal growth was achieved at the end of the process.

The clinical superiority of single- versus dualrod MCGR techniques is still controversial. ${ }^{[19]}$ Few studies have discussed single and double rods separately so far. Studies on the TGR technique supported the idea that the dual-rod structure provides a low rod fracture rate, better deformity correction, and higher spinal growth. ${ }^{[27]}$ While no significant difference was noted in the correction of the Cobb angle between the patients who received single- or double-rod structures in MCGR by Akbarnia et al., ${ }^{[19]}$ Dannawi et al. ${ }^{[11]}$ reported that the average improvement was significantly better in the dual-rod group. In the aforementioned studies, a better initial correction of coronal deformity and monthly increase in T1-T12 and T1-S1 were also observed in patients with the double rods. In addition, few articles in the literature divided primary and conversion groups in the MCGR analysis..$^{[8,20,28]}$ Keskinen et al., ${ }^{[23]}$ in their study of 27 primary and 23 conversion groups with multicentric MCGR, concluded that the deformity could be controlled equally in both groups, although the initial spinal growth was less in conversion patients, compared to the primary group. One of the strengths of this study was that the patient group consisted of primary cases and was treated with the dual MCGR technique. However, it should be kept in mind that not all patients are good candidates for dual-rod instrumentation.

One of the main concerns of the MCGR technique is the high complication rates. However, it is still unclear whether the complication rate in MCGR patients is different from the TGR technique. In a systematic review performed by Thakar et al., ${ }^{[29]}$ MCGR had a $44.5 \%$ cumulative surgical complication risk and a 33\% unplanned reoperation rate. The most common complications reported in the literature are screw or hook pull-out (11.8\%), backtracking of the rod $(11.7 \%)$, and rod breakage (10.6\%). ${ }^{[2]}$ Although high complication rates have been reported in both techniques, MCGR has been shown to have fewer implant-related infections and mechanical complications, compared to TGR. ${ }^{[29,30]}$ In our series, four complications $(26.7 \%)$ were observed. One of 
these complications was superficial surgical wound infection which resolved with oral antibiotics and wound care, while the others were mechanical complications. Compared to the literature, one reason for the low complication rate of the current study and the absence of rod breakage could be the use of rigid thoracolumbosacral orthosis until the sixth month. Another reason could be that we used the dual-rod technique in all patients, as we consider that it has a better deformity correction capability, fewer complications, and less failure rate, and all patients were suitable for using dual rods. ${ }^{[28]}$ In addition, in our study, we provided the anchors in both proximal and distal segments with pedicle screws in all patients.

The main advantage of the MCGR technique is to reduce the psychosocial burden and complications such as autofusion, adverse surgical infection, and thoracic insufficiency syndrome caused by TGR by reducing the number of operations. ${ }^{[31]}$ The main disadvantage of MCGR technique is its high cost. However, repeated surgical procedures, associated complications, and revision surgeries make TGR more expensive than the MCGR. Oetgen et al. ${ }^{[32]}$ and the National Institute for Health and Clinical Excellence (NICE) cost modeling carried out by Jenks et al. ${ }^{[33]}$ showed that, although MCGR was more expensive initially, the cumulative cost decreased after the third year. ${ }^{[34]}$ Consistent with the literature, in our study, the dual MCGR technique was found to be a competent, reliable, and robust treatment alternative for EOS.

Another disadvantage of MCGR is the radiation exposure due to frequently taken X-rays. Radiographs inevitably expose this group of children to a certain amount of radiation. Hickey et al. ${ }^{[8]}$ used ultrasound to measure rod distraction. This appears to be as accurate a method of measuring rod length and increase in length as standard radiographs. It has also a high intra- and inter-observer reliability and does not expose the child to radiation. ${ }^{[3,36]}$ On the other hand, this method of monitorization requires the input of an experienced radiologist. The EOS Imaging System has been available since 2007 and provides high-quality radiographs, a three-dimensional (3D) quantitative analysis of deformities, and a low exposure to radiation. ${ }^{[37,38]}$ It has also a good intraand inter-observer reproducibility and can be used in MCGR patients. ${ }^{[39]}$ The 3D changes with MCGR are mainly observed with initial rod implantation, and no significant changes are observed with distractions. The MCGR can prevent deformity progression in the axial plane. ${ }^{[40]}$
One of the features that made the current study valuable is that the patients were evaluated both radiologically and functionally. In the current study, the EOSQ-24 scores of EOS patients treated with MCGR showed a significant increase in all subdomains, except for the financial impact. The reason why families did not suffer from financial difficulties due to scoliosis surgery may be that the treatment costs of all patients participating in the study are covered by government-regulated insurance companies.

To the best of our knowledge, there are only several studies in the literature reporting spinal fusion results after MCGR and corrections have been shown on both deformity and lengthening. Lampe et al. ${ }^{[41]}$ reported that the spinal fusion of patients with MCGR resulted in 36\% additional correction in the Cobb angle. In the current study, the change in Cobb angle after spinal fusion surgery was $30.1 \%$. The T1-12 and T1-S1 lengthening gain were $12.5 \mathrm{~mm}$ and $20.8 \mathrm{~mm}$, respectively.

In the literature, there are no long-term follow-up data for MCGR. In previous studies, follow-up durations ranged from 10 to 48 months. ${ }^{[19,24]}$ However, the nature of the procedure completed due to the ending of spinal growth may not be possible to reach longer follow-up times.

The main limitations of the present study are the limited number of patients, the relatively short follow-up duration, and its retrospective design. However, the rarity of the disease, unexpected surgeries due to complications and the treatment method design are the main reasons for these limitations. Heterogeneity of the disease etiologies and the lack of statistical comparison of MCGR to TGR are the other limitations. On the other hand, the main strength of this study is reporting of spinal fusion surgery results of $46.6 \%$ of patients. Besides, the differences in deformity and complications of surgery were discussed in detail. A substantial aspect of the study is that a single surgical team performs all procedures on a relatively homogeneous patient group with a dual-rod structure.

In conclusion, the dual MCGR technique was a competent, reliable, and robust treatment alternative for EOS. It is possible to prevent deformity progression during skeletal growth without any loss of the ability to lengthen using MCGR. Internal fixation of deformity can be maintained with MCGR, even after the lengthening is complete. However, surgeons performing the MCGR technique should be aware 
of procedure-related complications. Although deformity correction can be achieved with spinal fusion surgery, the alterations of deformity are limited compared to the index surgery.

\section{Declaration of conflicting interests}

The authors declared no conflicts of interest with respect to the authorship and/or publication of this article.

\section{Funding}

The authors received no financial support for the research and/or authorship of this article.

\section{REFERENCES}

1. Williams BA, Matsumoto H, McCalla DJ, Akbarnia BA, Blakemore LC, Betz RR, et al. Development and initial validation of the Classification of Early-Onset Scoliosis (C-EOS). J Bone Joint Surg [Am] 2014;96:1359-67.

2. Skaggs D, Guillaume T, El-Hawary R, Emans J, Mendelow M, Smith JT. Early onset scoliosis consensus statement, SRS growing spine committee. Spine Deformity 2015;3:107.

3. Mayer O, Campbell R, Cahill P, Redding G. Thoracic insufficiency syndrome. Curr Probl Pediatr Adolesc Health Care 2016;46:72-97.

4. Karol LA, Johnston C, Mladenov K, Schochet P, Walters P, Browne RH. Pulmonary function following early thoracic fusion in non-neuromuscular scoliosis. J Bone Joint Surg [Am] 2008;90:1272-81.

5. Helenius IJ. Standard and magnetically controlled growing rods for the treatment of early onset scoliosis. Ann Transl Med 2020;8:26.

6. Skaggs DL, Akbarnia BA, Flynn JM, Myung KS, Sponseller PD, Vitale MG; Chest Wall and Spine Deformity Study Group; Growing Spine Study Group; Pediatric Orthopaedic Society of North America; Scoliosis Research Society Growing Spine Study Committee. A classification of growth friendly spine implants. J Pediatr Orthop 2014;34:260-74.

7. Bess S, Akbarnia BA, Thompson GH, Sponseller PD, Shah $\mathrm{SA}, \mathrm{El}$ Sebaie $\mathrm{H}$, et al. Complications of growing-rod treatment for early-onset scoliosis: Analysis of one hundred and forty patients. J Bone Joint Surg [Am] 2010;92:2533-43.

8. Hickey BA, Towriss C, Baxter G, Yasso S, James S, Jones A, et al. Early experience of MAGEC magnetic growing rods in the treatment of early onset scoliosis. Eur Spine J 2014;23 Suppl 1:S61-5.

9. Akbarnia BA, Mundis GM Jr, Salari P, Yaszay B, Pawelek JB. Innovation in growing rod technique: A study of safety and efficacy of a magnetically controlled growing rod in a porcine model. Spine (Phila Pa 1976) 2012;37:1109-14.

10. Cheung KM, Cheung JP, Samartzis D, Mak KC, Wong YW, Cheung WY, et al. Magnetically controlled growing rods for severe spinal curvature in young children: A prospective case series. Lancet 2012;379:1967-74.

11. Dannawi Z, Altaf F, Harshavardhana NS, El Sebaie H, Noordeen $\mathrm{H}$. Early results of a remotely-operated magnetic growth rod in early-onset scoliosis. Bone Joint J 2013;95B:75-80.

12. Dimeglio A, Canavese F. The growing spine: How spinal deformities influence normal spine and thoracic cage growth. Eur Spine J 2012;21:64-70.
13. Dimeglio A, Canavese F. The immature spine: Growth and idiopathic scoliosis. Ann Transl Med 2020;8:22.

14. Cobb J. Outlines for the study of scoliosis measurements from spinal roentgenograms. Phys Ther 1948;59:764-5.

15. Thompson GH, Akbarnia BA, Kostial P, Poe-Kochert C, Armstrong DG, Roh J, et al. Comparison of single and dual growing rod techniques followed through definitive surgery: A preliminary study. Spine (Phila Pa 1976) 2005;30:2039-44.

16. Matsumoto H, Williams B, Park HY, Yoshimachi JY, Roye $\mathrm{BD}$, Roye DP Jr, et al. The final 24-Item Early Onset Scoliosis Questionnaires (EOSQ-24): Validity, reliability and responsiveness. J Pediatr Orthop 2018;38:144-51.

17. Demirkiran HG, Kinikli GI, Olgun ZD, Kamaci S, Yavuz Y, Vitale MG, et al. Reliability and validity of the adapted Turkish version of the Early-Onset Scoliosis-24-Item Questionnaire (EOSQ-24). J Pediatr Orthop 2015;35:804-9.

18. Smith JT, Johnston C, Skaggs D, Flynn J, Vitale M. A new classification system to report complications in growing spine surgery: A multicenter consensus study. J Pediatr Orthop 2015;35:798-803.

19. Akbarnia BA, Cheung K, Noordeen H, Elsebaie H, Yazici M, Dannawi Z, et al. Next generation of growth-sparing techniques: Preliminary clinical results of a magnetically controlled growing rod in 14 patients with early-onset scoliosis. Spine (Phila Pa 1976) 2013;38:665-70.

20. Thompson W, Thakar C, Rolton DJ, Wilson-MacDonald J, Nnadi C. The use of magnetically-controlled growing rods to treat children with early-onset scoliosis: Early radiological results in 19 children. Bone Joint J 2016;98B:1240-7.

21. Lebon J, Batailler C, Wargny M, Choufani E, Violas P, Fron $\mathrm{D}$, et al. Magnetically controlled growing rod in early onset scoliosis: A 30-case multicenter study. Eur Spine J 2017;26:1567-76.

22. Ridderbusch K, Rupprecht M, Kunkel P, Hagemann C, Stücker R. Preliminary results of magnetically controlled growing rods for early onset scoliosis. J Pediatr Orthop 2017;37:e575-e580.

23. Keskinen H, Helenius I, Nnadi C, Cheung K, Ferguson J, Mundis G, et al. Preliminary comparison of primary and conversion surgery with magnetically controlled growing rods in children with early onset scoliosis. Eur Spine J 2016;25:3294-300.

24. Teoh KH, Winson DM, James SH, Jones A, Howes J, Davies $\mathrm{PR}$, et al. Magnetic controlled growing rods for early-onset scoliosis: A 4-year follow-up. Spine J 2016;16(4 Suppl):S34-9.

25. Rolton D, Thakar C, Wilson-MacDonald J, Nnadi C. Radiological and clinical assessment of the distraction achieved with remotely expandable growing rods in early onset scoliosis. Eur Spine J 2016;25:3371-6.

26. Ahmad A, Subramanian T, Panteliadis P, WilsonMacdonald J, Rothenfluh DA, Nnadi C. Quantifying the 'law of diminishing returns' in magnetically controlled growing rods. Bone Joint J 2017;99-B:1658-64.

27. Yang JS, Sponseller PD, Thompson GH, Akbarnia BA, Emans JB, Yazici M, et al. Growing rod fractures: Risk factors and opportunities for prevention. Spine (Phila Pa 1976) 2011;36:1639-44.

28. Subramanian T, Ahmad A, Mardare DM, Kieser DC, Mayers D, Nnadi C. A six-year observational study of 31 children with early-onset scoliosis treated using magnetically 
controlled growing rods with a minimum follow-up of two years. Bone Joint J 2018;100-B:1187-200.

29. Thakar C, Kieser DC, Mardare M, Haleem S, Fairbank J, Nnadi C. Systematic review of the complications associated with magnetically controlled growing rods for the treatment of early onset scoliosis. Eur Spine J 2018;27:2062-71.

30. Choi E, Yaszay B, Mundis G, Hosseini P, Pawelek J, Alanay A, et al. Implant complications after magnetically controlled growing rods for early onset scoliosis: A multicenter retrospective review. J Pediatr Orthop 2017;37:e588-e592.

31. Teli M, Grava G, Solomon V, Andreoletti G, Grismondi E, Meswania J. Measurement of forces generated during distraction of growing-rods in early onset scoliosis. World J Orthop 2012;3:15-9.

32. Oetgen ME, McNulty EM, Matthews AL. Cost-effectiveness of magnetically controlled growing rods: Who really benefits? Spine Deform 2019;7:501-4.

33. Jenks M, Craig J, Higgins J, Willits I, Barata T, Wood H, et al. The MAGEC system for spinal lengthening in children with scoliosis: A NICE medical technology guidance. Appl Health Econ Health Policy 2014;12:587-99.

34. Atik OŞ. What are the expectations of an editor from a scientific article? Jt Dis Relat Surg 2020;31:597-8.

35. Yoon WW, Chang AC, Tyler P, Butt S, Raniga S, Noordeen $\mathrm{H}$. The use of ultrasound in comparison to radiography in magnetically controlled growth rod lengthening measurement: A prospective study. Eur Spine J 2015;24:1422-6.

36. Stokes OM, O'Donovan EJ, Samartzis D, Bow CH, Luk KD, Cheung KM. Reducing radiation exposure in early-onset scoliosis surgery patients: Novel use of ultrasonography to measure lengthening in magnetically-controlled growing rods. Spine J 2014;14:2397-404.

37. Escott BG, Ravi B, Weathermon AC, Acharya J, Gordon CL, Babyn PS, et al. EOS low-dose radiography: A reliable and accurate upright assessment of lower-limb lengths. J Bone Joint Surg [Am] 2013;95:e1831-7.

38. Faria R, McKenna C, Wade R, Yang H, Woolacott N, Sculpher M. The EOS 2D/3D X-ray imaging system: A costeffectiveness analysis quantifying the health benefits from reduced radiation exposure. Eur J Radiol 2013;82:e342-9.

39. Ilharreborde B, Dubousset J, Le Huec JC. Use of EOS imaging for the assessment of scoliosis deformities: application to postoperative 3D quantitative analysis of the trunk. Eur Spine J 2014;23 Suppl 4:S397-405.

40. Cheung JPY, Cheung PWH, Cheung KMC. The effect of magnetically controlled growing rods on three-dimensional changes in deformity correction. Spine Deform 2020;8:537-46.

41. Lampe LP, Schulze Bövingloh A, Gosheger G, Schulte TL, Lange T. Magnetically controlled growing rods in treatment of early-onset scoliosis: A single center study with a minimum of 2-year-follow up and preliminary results after converting surgery. Spine (Phila Pa 1976) 2019;44:1201-10. 